http://jmscr.igmpublication.org/home/ ISSN (e)-2347-176x ISSN (p) 2455-0450 crossref DOI: https://dx.doi.org/10.18535/jmscr/v7i10.147

\title{
Spectrum of Pulmonary Thromboembolism at Different Levels
}

\author{
Authors \\ Dr Kantheti Anusha Junior Resident, Dr Kuncham Nagabalaji \\ Yashoda Hospitals Malakpet, Telengana, India
}

\begin{abstract}
Aims and Objectives: Role of CT Pulmonary Angiography in diagnosis of pulmonary thromboembolism. Content: Pulmonary thromboembolism (PE) is a frequently occuring disease caused by obstruction of a pulmonary artery by a thrombus. PE is potentially lethal disease. Of all patients who develop PE, it directly causes or contributes to the patient's death in one-third of the cases. The role of CT in diagnosis of thromoembolism at different levels of pulmonary trunk involving main trunk, Right pulmonary artery, Left pulmonary artery, saddle thrombus, thrombus involving segmental and sub segmental branches is evaluated.

Summary: The chest radiograph is of limited value. It may be normal or reveal non-specific atelectasis CT Pulmonary Angiography is preferred imaging modality for diagnosis of pulmonary thromboembolism. Aims and Objectives: Role of CT Pulmonary Angiography in diagnosis of pulmonary thromboembolism Content: Pulmonary thromboembolism (PE) is a frequently occurring disease caused by obstruction of a pulmonary artery by a thrombus. The role of CT in diagnosis of thromoembolism at different levels of pulmonary trunk involving main trunk, Right pulmonary artery, Left pulmonary artery, saddle thrombus, thrombus involving segmental and sub segmental branches is evaluated.
\end{abstract}

\section{Introduction}

Pulmonary embolism refers to the embolic occlusion of pulmonary arterial system. While the majority of cases result from thrombotic occlusion, this condition is frequently referred to as pulmonary thromboembolism.

\section{On CT}

The only primary sign of PTE is a filling defect. Secondary signs are the abrupt occlusion of pulmonary artery and areas of oligaemia with pruning of branching vessels.

\section{Case- 1}

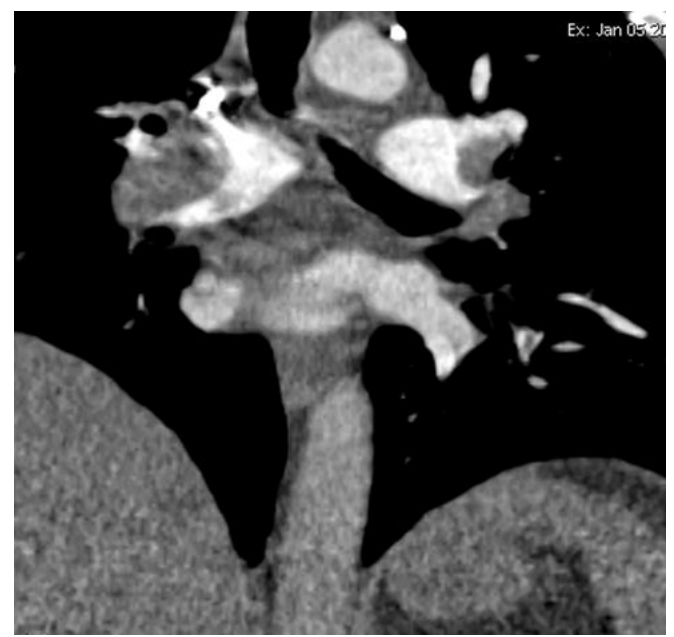




\section{JMSCR Vol||07||Issue\|10||Page 860-863\|October}
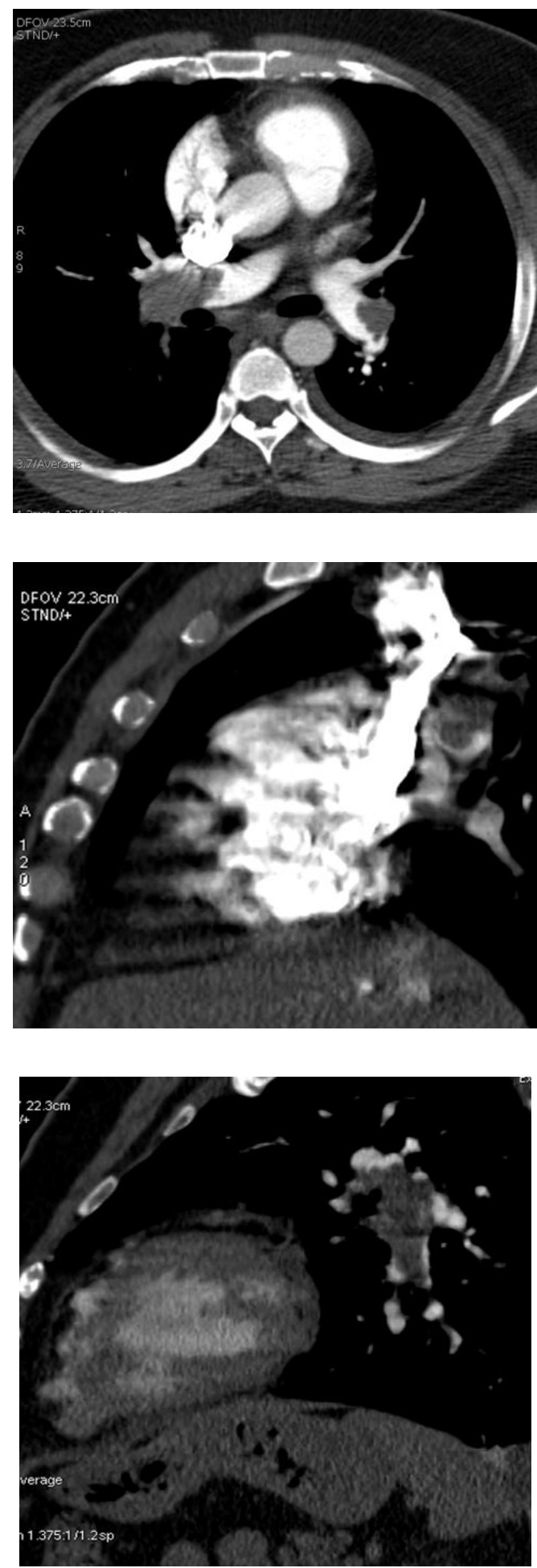

Case of 33 yr male with chest pain, CT pulmonary angio showing thrombus in right and left pulmonary arteries extending into lobar arteries.

\section{Case 2}
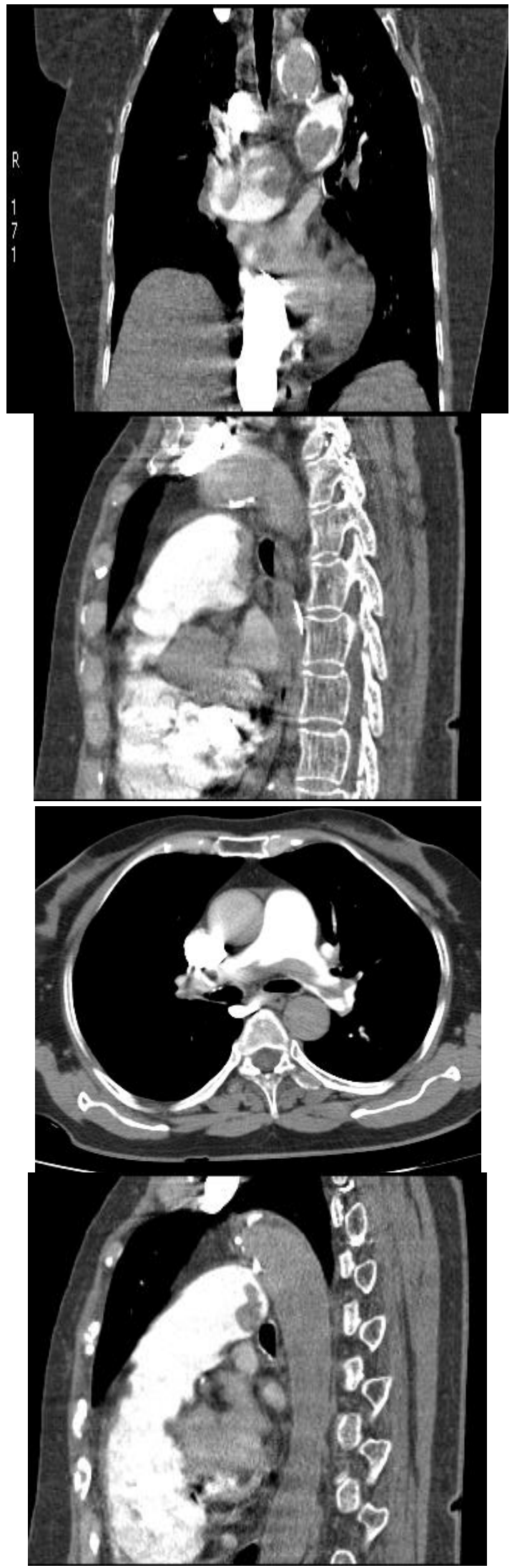

Case of $70 \mathrm{yr}$ female with breathlessness, CT pulmonary angio showing thrombus in main, right and left pulmonary arteries - Saddle thrombus 


\section{JMSCR Vol||07||Issue ||10||Page 860-863||October}

Case- 3

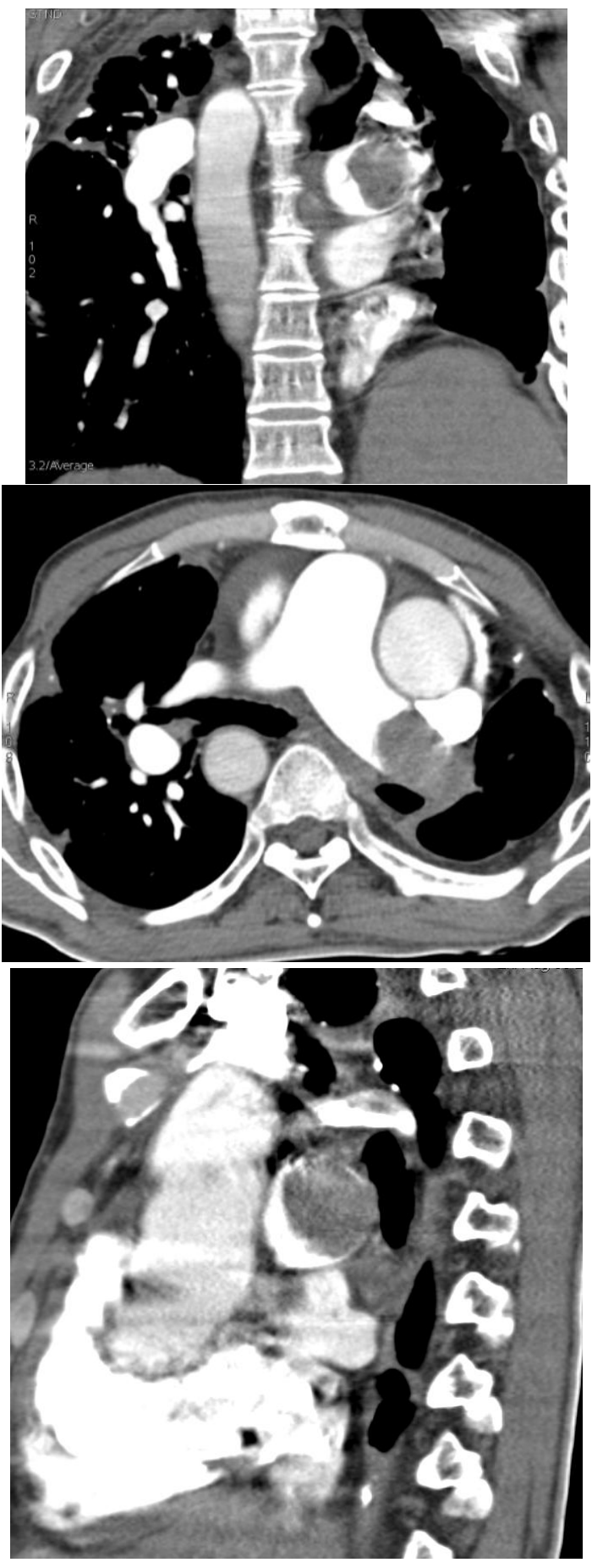

Case of $63 \mathrm{yr}$ male with situsinversus total is showing near total thrombotic occlusion of Morphological right sided main pulmonary artery extending into segmental arteries on CT pulmonary angiogram.
Case-4

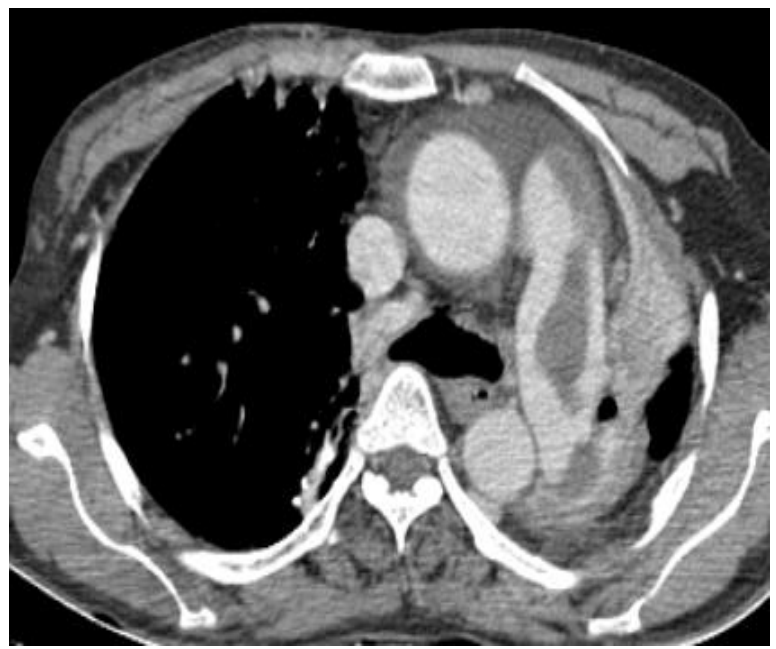

Case of $45 \mathrm{yr}$ female, CT pulmonary angio showing thrombus in left main pulmonary artery.

\section{Case 5}

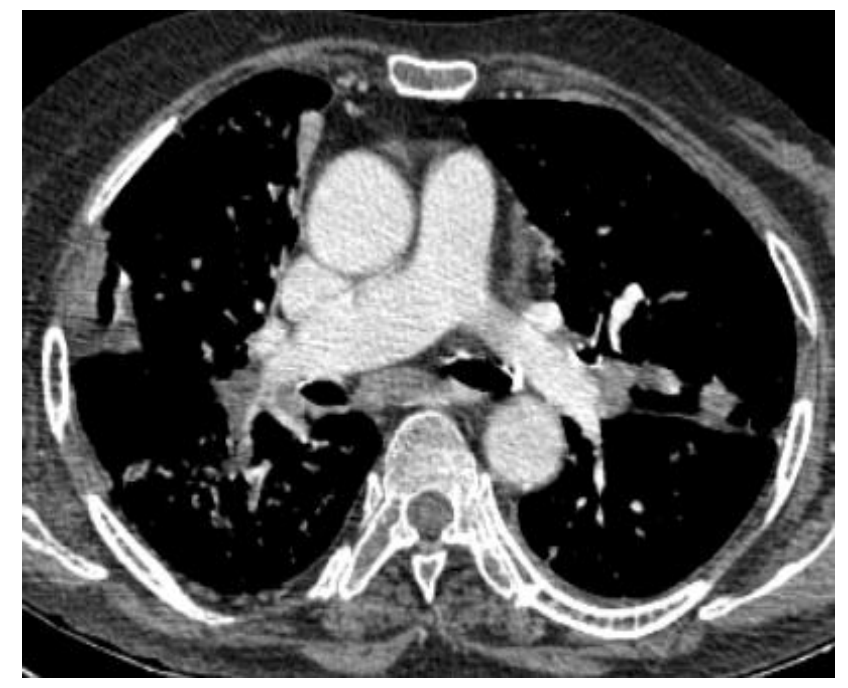

Case of $60 \mathrm{yr}$ female with breathlessness and venous thrombosis, CT pulmonary angio showing thrombus in segmental arteries of bilateral lower lobes.

\section{Summary}

The chest radiograph is of limited value. It may be normal or reveal non specific atelectasis. CT pulmonary Angiography is preferred imaging modality for diagnosis of pulmonary thrmboembolism 


\section{References}

1. Stein PD, Woodard PK, Weg JG et-al. diagnostic pathways in acute pulmonary embolism: recommendations of the PIOPED II investigators-Jan 2007 volume 242.

2. Han D, Lee KS, Franquet $\mathrm{T}$ et-al. Thrombotic and non thrmbotic pulmonary arterial embolism: Spectrum of imaging findings. radiographicsnov 2003 volume 23. 